\title{
The effect of switchgrass loadings on feedstock solubilization and biofuel production by Clostridium thermocellum
}

Tobin J. Verbeke1,2,3, Gabriela M. Garcia ${ }^{1,2}$ and James G. Elkins ${ }^{1,2^{*}}$

\begin{abstract}
Background: Efficient deconstruction and bioconversion of solids at high mass loadings is necessary to produce industrially relevant titers of biofuels from lignocellulosic biomass. To date, only a few studies have investigated the effect of solids loadings on microorganisms of interest for consolidated bioprocessing. Here, the effects that various switchgrass loadings have on Clostridium thermocellum solubilization and bioconversion are investigated.

Results: Clostridium thermocellum was grown for 10 days on 10,25, or $50 \mathrm{~g} / \mathrm{L}$ switchgrass or Avicel at equivalent glucan loadings. Avicel was completely consumed at all loadings, but total cellulose solubilization decreased from 63 to $37 \%$ as switchgrass loadings increased from 10 to $50 \mathrm{~g} / \mathrm{L}$. Washed, spent switchgrass could be additionally hydrolyzed and fermented in second-round fermentations suggesting that access to fermentable substrates was not the limiting factor at higher feedstock loadings. Results from fermentations on Avicel or cellobiose using culture medium supplemented with 50\% spent fermentation broth demonstrated that compounds present in the supernatants from the 25 or $50 \mathrm{~g} / \mathrm{L}$ switchgrass loadings were the most inhibitory to continued fermentation.
\end{abstract}

Conclusions: Recalcitrance alone cannot fully account for differences in solubilization and end-product formation between switchgrass and Avicel at increased substrate loadings. Experiments aimed at separating metabolic inhibition from inhibition of hydrolysis suggest that $C$. thermocellum's hydrolytic machinery is more vulnerable to inhibition from switchgrass-derived compounds than its fermentative metabolism.

Keywords: Clostridium thermocellum, Consolidated bioprocessing, Switchgrass, Recalcitrance, Inhibition, High-solid loading, Ethanol

\section{Background}

Efficient plant cell-wall deconstruction and solubilization is a major challenge to overcome when converting lignocellulosic feedstocks to renewable fuels and chemicals. One promising low-cost strategy to produce cellulosic ethanol through bioconversion is consolidated bioprocessing (CBP), which relies on the simultaneous solubilization and fermentation of lignocellulose carbohydrate polymers without additional enzymes [1]. The hydrolytic capabilities of the thermophile, Clostridium (Ruminiclostridium) thermocellum have identified this

\footnotetext{
*Correspondence: elkinsjg@ornl.gov

2 Biosciences Division, Oak Ridge National Laboratory, Oak Ridge, TN 37831-6038, USA

Full list of author information is available at the end of the article
}

bacterium as a particularly capable organism for CBP $[2$, 3]. In addition, genetic engineering efforts have improved the bacterium's abilities to detoxify pretreatment derived inhibitors [4] as well as to achieve high ethanol yields and titers simultaneously $[1,5]$.

Differences in feedstock type and composition [6-8], time of harvest $[3,9]$ and pretreatment strategies $[10$, 11 ] have all been previously assessed in regard to $C$. thermocellum-mediated conversion to ethanol. However, little has been reported regarding the effect that substrate loading has on C. thermocellum solubilization and biofuel production despite the realization that feedstock loadings in excess of $>100 \mathrm{~g} / \mathrm{L}$ carbohydrate are considered essential for industrialization and economic viability of cellulosic ethanol $[12,13]$. Furthermore, studies that 
have looked at differences in substrate loadings have typically employed model cellulosic substrates or soluble cellodextrins and have principally focused on end-product distribution profiles $[1,12,14,15]$.

High-solid fermentations of real-world biomass are known to produce a variety of challenges to biocatalysts. For example, soluble sugar accumulation [16, 17], reductions in enzyme adsorption [18], and end-product induced cellulase inactivation [19] have all been reported to adversely affect solubilization by systems employing fungal enzymes. Only a few studies investigating solids loadings on CBP-candidate microbes have been reported to date, however. Using Clostridium phytofermentans, decreased sugar conversion efficiencies were observed as loadings of washed, pretreated corn stover increased [20]. The reduction in conversion efficiency observed was attributed to an accumulation of the fermentation product acetate, which was proposed to principally inhibit the strain's solubilization machinery, rather than its ability to metabolically ferment the saccharides. Amongst CBPrelevant thermophiles, Caldicellulosiruptor bescii has been reported to grow on unpretreated switchgrass at concentrations as high as $200 \mathrm{~g} / \mathrm{L}$ [21, 22]. Furthermore, solubilization efficiencies (27-33\%) remained consistent for the bacterium at biomass loadings ranging from 1 to $50 \mathrm{~g} / \mathrm{L}$ switchgrass with improved overall conversions achievable through biomass washing and repetitive fermentations. It was, however, unclear why individual fermentations stopped at $\sim 30 \%$ solubilization, though an unidentified inhibitor associated with spent fermentation broths was noted [21].

The recalcitrance barrier is one that all bioconversion strategies face, though the magnitude of this barrier is known to vary widely [3]. Similarly, the processes affected by high-solid loading induced inhibition can also vary depending on the feedstock, process configuration, and biocatalyst. The intent of this study is to provide an initial assessment of the effects that varied biomass loadings of "minimally-pretreated" (autoclaved) switchgrass have on C. thermocellum's solubilization and conversion capabilities. It further seeks to provide insight into what processes are most vulnerable to inhibition at increased loadings.

\section{Results}

Batch fermentations of minimally pretreated switchgrass or Avicel were run in parallel to compare solubilization and biofuel production by $C$. thermocellum. The glucan contents were normalized between comparator fermentations based on a reported glucan content of $35 \%$ cellulose in the Alamo cultivar [22-24]. At 3.5, 8.8, and $17.5 \mathrm{~g} / \mathrm{L}$ of Avicel, the ethanol yields for C. thermocellum M1570 ranged from 50 to $60 \%$ of the theoretical maximum, which is consistent with previous reports for the strain [25]. In the switchgrass fermentations, however, there was a significant drop in the overall ethanol titer (Fig. 1). At 10, 25, and $50 \mathrm{~g} / \mathrm{L}$ loadings, ethanol titers decreased by 41,48 , and $69 \%$, respectively, relative to those observed in the corresponding Avicel fermentations. Mass-balance analyses confirmed that the increased switchgrass loadings affected ethanol production, but also decreased total fermentation end-products by 21,33 , and $59 \%$ in the 10,25 , and $50 \mathrm{~g} / \mathrm{L}$ switchgrass loadings, respectively (Table 1 ).

Near complete glucan utilization was observed in the Avicel fermentations (Table 1). Five-to-eight percent of the initial substrate mass was recovered in the cell pellet fraction after 10 days of fermentation, which is consistent with the expected amounts of biomass produced by C. thermocellum growth [26, 27]. Only minor amounts of glucose equivalents were observed in the remaining supernatant fraction. This was in stark contrast to the switchgrass fermentations, where significant quantities
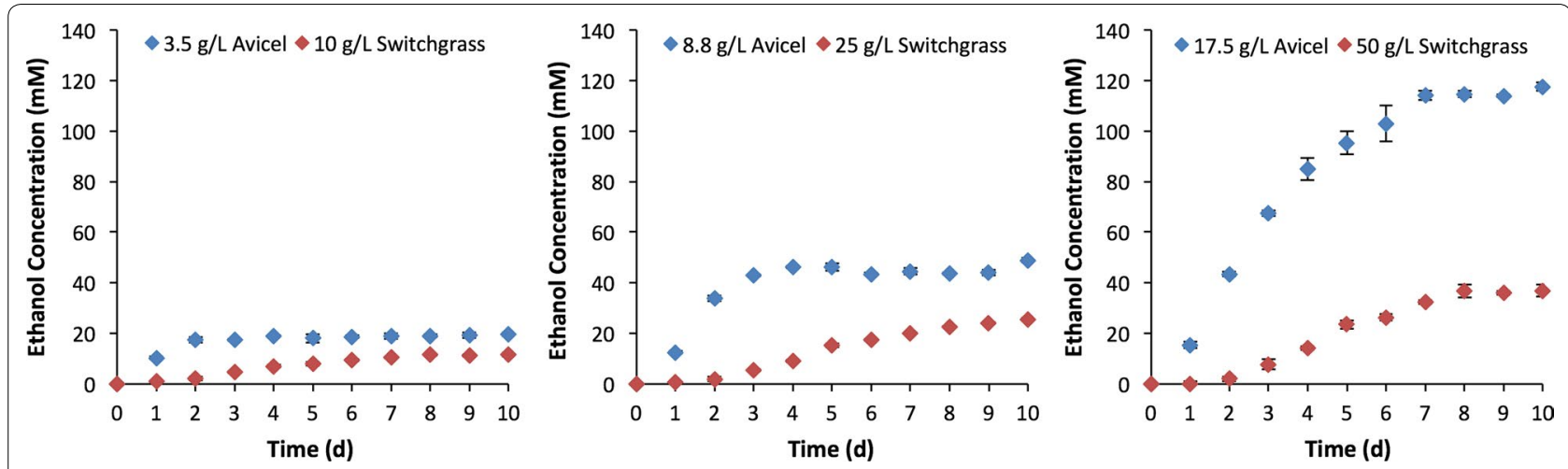

Fig. 1 Net ethanol production by C. thermocellum M1570 under various substrate loadings. For all graphs, the glucan content in the Avicel fermentations is equivalent to those in the switchgrass fermentations at the corresponding loading. Values are averages of triplicate fermentations and error bars represent standard deviation 
Table 1 Mass-balance analyses of Avicel and switchgrass fermentations

\begin{tabular}{|c|c|c|c|c|c|c|}
\hline Condition & $\begin{array}{l}\text { Initial substrate/ } \\
\text { biomass (mg) }\end{array}$ & $\begin{array}{l}\text { Residual substrate/ } \\
\text { biomass }+ \text { cell dry } \\
\text { weight }(\mathrm{mg})\end{array}$ & $\begin{array}{l}\text { Soluble glucose } \\
\text { and xylose equivalents } \\
\text { recovered (mg) }\end{array}$ & $\begin{array}{l}\text { Fermentation } \\
\text { products } \\
\text { recovered }(\mathrm{mg})^{\mathrm{a}}\end{array}$ & $\begin{array}{l}\text { Carbon } \\
\text { recovery (\%) }\end{array}$ & Final $\mathrm{pH}$ \\
\hline $3.5 \mathrm{~g} / \mathrm{L}$ Avicel & 175.0 & $13.8 \pm 1.1$ & $5.0 \pm 0.1$ & $90.4 \pm 2.9$ & $62.4 \pm 2.8$ & $7.0 \pm 0.0$ \\
\hline $8.8 \mathrm{~g} / \mathrm{L}$ Avicel & 440.0 & $30.7 \pm 0.6$ & $4.1 \pm 0.3$ & $225.1 \pm 10.6$ & $59.1 \pm 2.8$ & $6.8 \pm 0.0$ \\
\hline $17.5 \mathrm{~g} / \mathrm{L}$ Avicel & 875.0 & $44.9 \pm 1.3$ & $1.5 \pm 0.1$ & $548.0 \pm 6.1$ & $67.9 \pm 2.4$ & $6.0 \pm 0.0$ \\
\hline $10 \mathrm{~g} / \mathrm{L} \mathrm{SG}$ & 500.0 & $297.9 \pm 12.0$ & $124.1 \pm 16.2$ & $71.0 \pm 7.3$ & $98.6 \pm 8.9$ & $7.1 \pm 0.0$ \\
\hline $25 \mathrm{~g} / \mathrm{L} \mathrm{SG}$ & 1250.0 & $811.1 \pm 7.7$ & $179.2 \pm 14.0$ & $150.8 \pm 2.2$ & $91.3 \pm 3.1$ & $6.8 \pm 0.0$ \\
\hline $50 \mathrm{~g} / \mathrm{L} \mathrm{SG}$ & 2500.0 & $1768.8 \pm 10.7$ & $285.6 \pm 11.3$ & $223.3 \pm 11.6$ & $91.1 \pm 2.9$ & $6.6 \pm 0.0$ \\
\hline
\end{tabular}

Values are averages $(n=3) \pm S D$

SG switchgrass

a Sum total of net acetate, lactate, formate, ethanol, and $\mathrm{CO}_{2}$ production. $\mathrm{CO}_{2}$ was estimated based on the formula: $\mathrm{CO}_{2}=$ acetate + ethanol-formate

of soluble sugars were recovered. For the switchgrass fermentations, 39, 53, and $97 \mathrm{mg}$ of glucose equivalents, as well as 85,127 , and $189 \mathrm{mg}$ of xylose equivalents, were recovered in the 10,25 , and $50 \mathrm{~g} / \mathrm{L}$ switchgrass loadings, respectively (Table 1 ). Together, these account for 25,14 , and $11 \%$ of the initial biomass provided in the 10,25 , and $50 \mathrm{~g} / \mathrm{L}$ conditions. A mass balance accounting for fermented and soluble residual glucans showed that 63,47 , and $37 \%$ of the total glucose equivalents were removed from the initial 10, 25, and $50 \mathrm{~g} / \mathrm{L}$ switchgrass loadings, respectively (Table 2 ).

The effective solubilization and fermentation of $17.5 \mathrm{~g} / \mathrm{L}$ Avicel by $C$. thermocellum suggested that the basis for inhibition in the switchgrass experiments was not related to end-product inhibition, nutrient availability, or $\mathrm{pH}$ limitation (Table 1). Additional experiments were then designed to determine the contribution that biomass recalcitrance, metabolic inhibition, and/or inhibition of hydrolysis contributed to the observed reduction in end-products formed.

To examine the contribution of recalcitrance, washed residual switchgrass recovered from the initial experiments was subjected to a second round of fermentation using fresh growth medium and $10 \mathrm{~g} / \mathrm{L}$ of the spent switchgrass. At equivalent solids loadings, the highest ethanol titer was observed in switchgrass recovered from the initial $50 \mathrm{~g} / \mathrm{L}$ fermentation (Fig. 2a). In terms

Table 2 Cellulose solubilization efficiencies under different switchgrass loadings

\begin{tabular}{lccc}
\hline & $\mathbf{1 0} \mathbf{~ g / L}$ & $\mathbf{2 5} \mathbf{~ g / L}$ & $\mathbf{5 0 ~} \mathbf{~ / ~}$ \\
\hline Solubilized glucans $^{\mathrm{a}}(\mathrm{mg})$ & 110.2 & 203.4 & 320.2 \\
Initial glucan (mg) & 175.0 & 437.5 & 875.0 \\
Solubilization efficiency (\%) & 63.0 & 46.5 & 36.6 \\
\hline
\end{tabular}

a Sum of fermentation end-products and solubilized, but non-fermented glucose equivalents

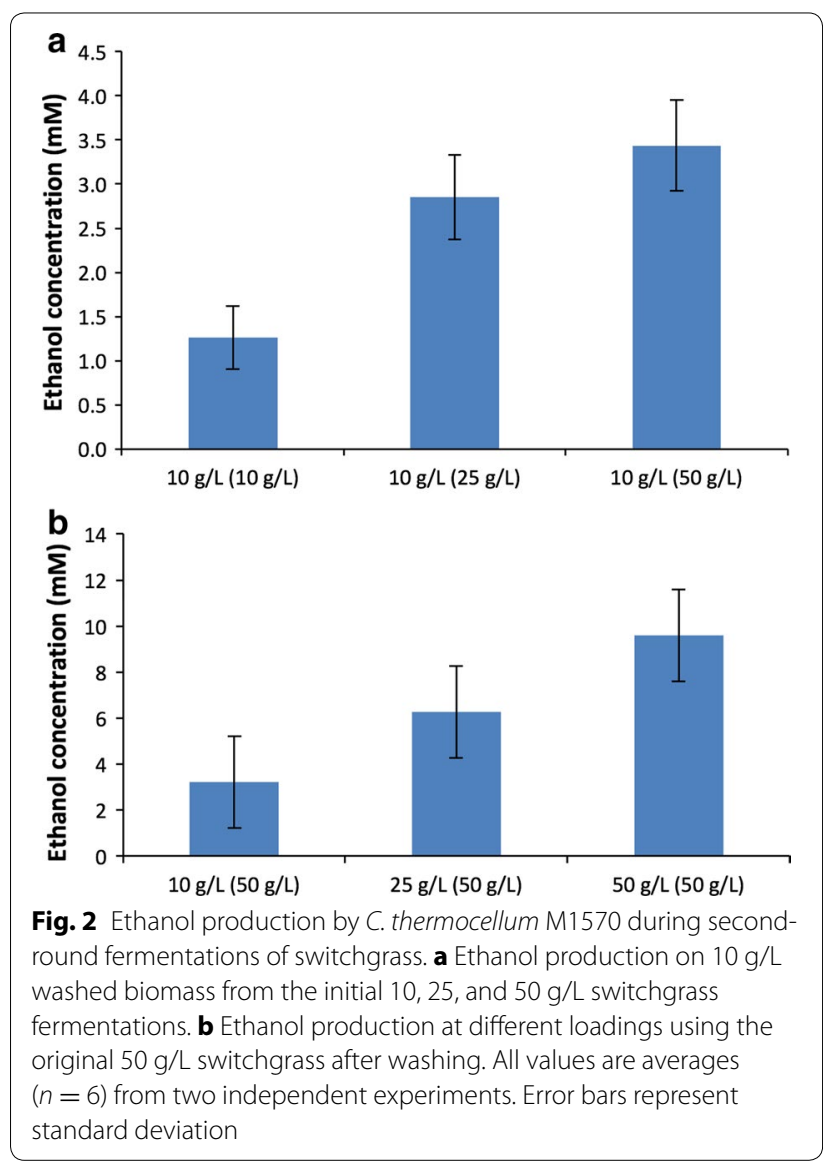

of efficiency, C. thermocellum was able to solubilize and ferment an additional 13,24 , and $23 \%$ of the remaining glucan equivalents after the initial 10, 25, and $50 \mathrm{~g} / \mathrm{L}$ switchgrass fermentations, respectively.

Varying levels of inhibition were observed based on differences in feedstock loading in the primary fermentations. By extension, residual glucan content of the spent feedstock would also then vary and be dependent on 
loading conditions. To account for variability in residual glucan content due to differences in first-round solubilization, an additional set of secondary fermentation experiments were conducted using residual switchgrass from the initial $50 \mathrm{~g} / \mathrm{L}$ loading only. As expected, the ethanol titers after a second 10-day fermentation were the greatest at the highest biomass loading (Fig. 2b). Despite the higher titers, however, the efficiency of sugar conversion to end-products once again decreased as biomass loading increased. Specifically, at second-round loadings of 10,25 , or $50 \mathrm{~g} / \mathrm{L}$ switchgrass, $C$. thermocellum solubilized and fermented an additional 22, 17, and $13 \%$ of the residual glucan.

Based on the hydrolysis and end-product formation profiles observed in the second-round fermentations, recalcitrance alone could not: (i) fully account for the differences in end-product titers observed in the initial switchgrass and Avicel fermentations or (ii) explain why ethanol titers plateaued during the first-round fermentations when glucans were still available for solubilization and conversion (Fig. 1). The potential for switchgrassderived compounds to inhibit $C$. thermocellum metabolism was then assessed. Culture broths comprised of $50 \%$ fresh growth medium and 50\% neutralized, spent broth from the initial fermentation were used. Cellobiose was provided as a soluble cellodextrin at a glucan loading equivalent to $17.5 \mathrm{~g} / \mathrm{L}$ Avicel. Under all conditions tested, $>95 \%$ of all available glucose equivalents provided were consumed (Table 3). Furthermore, significant ethanol production was observed with end-product ratios remaining relatively consistent across all conditions. The sole exception was the significant decrease in both ethanol and formate production in cultures containing 50\% supernatant derived from the original $17.5 \mathrm{~g} / \mathrm{L}$ Avicel fermentations. These lower titers were observed despite similar consumption of cellobiose relative to the other samples as well as the control. The reductions in titer represent changes in net production from cellobiose and do not account for residual end-products from the initial fermentations. For example, cultures with supernatant derived from the initial $17.5 \mathrm{~g} / \mathrm{L}$ Avicel fermentations only produced an additional $91.0 \pm 5.8 \mathrm{mM}$ of ethanol (Table 3), but the actual ethanol concentration in the fermentation medium was $150 \pm 6.1 \mathrm{mM}$ when accounting for ethanol produced in the first-round fermentations.

Next, inhibition of hydrolysis was examined using fermentation medium containing $50 \%$ spent broth (as above), but using $17.5 \mathrm{~g} / \mathrm{L}$ Avicel instead of cellobiose. The molar ethanol yields remained relatively consistent across all conditions with one exception (Fig. 3). Once again, the fermentation broth comprised of $50 \%$ spent supernatant from the original $17.5 \mathrm{~g} / \mathrm{L}$ Avicel fermentation showed less ethanol production than the other conditions. Specifically, a reduction in ethanol yield was observed (Fig. 3) that was similar to the reduction in titer determined from the cellobiose fermentations (Table 3).

Unlike the cellobiose fermentations, however, there was significant variation in the glucose equivalents remaining. Total Avicel solubilization was less for cultures containing supernatant from the initial switchgrass fermentations relative to those containing supernatant from the initial Avicel fermentations. The greatest reduction in solubilization was observed in cultures containing supernatant from the initial $50 \mathrm{~g} / \mathrm{L}$ switchgrass fermentations. Here, $\sim 22 \%$ less Avicel was hydrolyzed after 10 days of incubation than was observed in the control condition.

\section{Discussion}

The plant cell-wall solubilization efficacy of C. thermocellum has been well established with glucan utilization efficiencies up to $60-70 \%$ on multiple potential bioenergy crops, including switchgrass [3, 9, 28]. Recalcitrance alone, however, cannot fully account for the differences in fermentation end-product titers observed here between

Table 3 Net end-product formation of cellobiose ${ }^{a}$ fermentations containing $50 \%(v / v)$ of spent supernatant

\begin{tabular}{|c|c|c|c|c|c|c|c|}
\hline \multirow[t]{2}{*}{ Condition } & \multicolumn{6}{|c|}{ Concentration (mM) } & \multirow[t]{2}{*}{ Final $\mathrm{pH}$} \\
\hline & Ethanol & Formate & Acetate & Lactate & $\mathrm{CO}_{2}$ & $\begin{array}{l}\text { Glucose equivalents } \\
\text { remaining }\end{array}$ & \\
\hline Control & $116.5 \pm 5.5$ & $11.7 \pm 0.9$ & $4.0 \pm 0.6$ & $0.7 \pm 0.3$ & $108.8 \pm 9.9$ & $1.9 \pm 0.5$ & $6.2 \pm 0.0$ \\
\hline $3.5 \mathrm{~g} / \mathrm{L}$ Avicel & $110.7 \pm 4.1$ & $9.8 \pm 0.6$ & $3.2 \pm 0.3$ & $0.4 \pm 0.0$ & $104.1 \pm 6.6$ & $1.4 \pm 0.1$ & $6.2 \pm 0.0$ \\
\hline $8.8 \mathrm{~g} / \mathrm{L}$ Avicel & $100.1 \pm 1.8$ & $9.3 \pm 1.2$ & $3.5 \pm 0.2$ & $0.6 \pm 0.3$ & $94.3 \pm 8.4$ & $3.0 \pm 0.4$ & $6.1 \pm 0.0$ \\
\hline $17.5 \mathrm{~g} / \mathrm{L}$ Avicel & $91.0 \pm 5.8$ & $7.6 \pm 1.0$ & $4.1 \pm 0.8$ & $0.1 \pm 0.1$ & $87.5 \pm 11.3$ & $3.9 \pm 0.4$ & $6.0 \pm 0.0$ \\
\hline $10 \mathrm{~g} / \mathrm{L} \mathrm{SG}$ & $101.6 \pm 2.8$ & $11.5 \pm 1.7$ & $6.5 \pm 1.0$ & $0.7 \pm 0.2$ & $96.6 \pm 9.2$ & $1.8 \pm 0.7$ & $6.1 \pm 0.0$ \\
\hline $25 \mathrm{~g} / \mathrm{L} \mathrm{SG}$ & $101.4 \pm 1.3$ & $11.8 \pm 0.6$ & $4.8 \pm 0.4$ & $0.3 \pm 0.0$ & $94.4 \pm 8.3$ & $2.4 \pm 0.1$ & $6.1 \pm 0.1$ \\
\hline $50 \mathrm{~g} / \mathrm{L} \mathrm{SG}$ & $107.1 \pm 3.2$ & $9.4 \pm 0.9$ & $5.5 \pm 0.2$ & $0.4 \pm 0.0$ & $103.2 \pm 5.5$ & $4.6 \pm 0.4$ & $6.0 \pm 0.0$ \\
\hline
\end{tabular}

SG switchgrass

a Fermentations contained cellobiose at a concentration of $97 \mathrm{mM}$ glucose equivalents. $n=6$ 


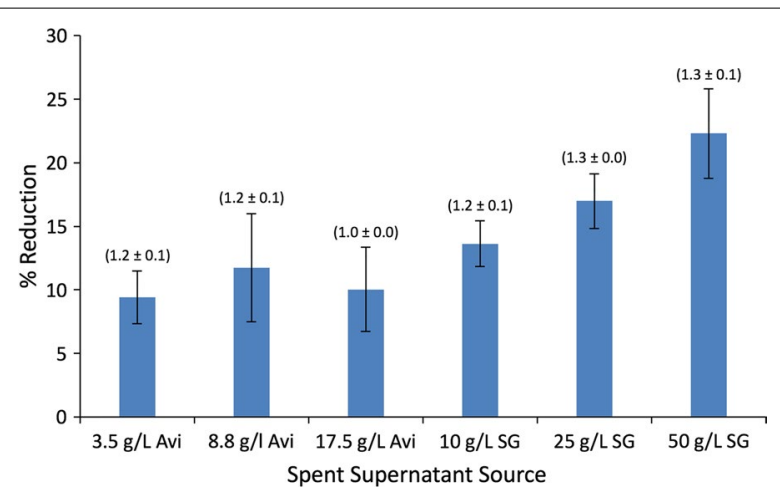

Fig. 3 Reduction in the solubilization efficiencies of $17.5 \mathrm{~g} / \mathrm{L}$ Avicel in fermentations containing $50 \%$ (v/v) spent supernatant. $X$-axis labels indicate the source of the spent supernatant from the first-round fermentation conditions used. Values in brackets above columns represent the molar ethanol production ratios ( $\mathrm{mM}$ ethanol produced: $\mathrm{mM}$ glucose equivalents consumed). Avi Avicel, SG switchgrass

the Avicel and switchgrass fermentations (Fig. 1, Table 1). If recalcitrance was the sole factor, it would be expected that total solubilization and end-product formation would scale linearly and proportionately with biomass loading. This was not the case, however. Instead, both total end-product yields and proportional solubilization efficiencies decreased as loadings increased (Table 1). This reduction in solubilization efficiency is similar to observations in free-enzyme systems $[16,18]$ as well as the CBP-candidate bacterium C. phytofermentans [20] under high-solid loading conditions.

The second-round fermentation experiments provided evidence that other factors, in addition to recalcitrance, were limiting end-product formation (Fig. 2). Here, the continued solubilization and end-product formation from the spent switchgrass confirmed that $C$. thermocellum's hydrolytic machinery was still capable of accessing fermentable substrates in the insoluble portion of the residual biomass. Despite the continued fermentation, however, the ethanol titers achieved during secondround fermentations (Fig. 2) could not fully account for differences in end-product titers observed in the initial switchgrass vs. Avicel comparison experiments (Fig. 1). Multiple possibilities can likely account for these differences. First, a certain proportion of the glucans in switchgrass remained inaccessible to hydrolysis and could not be solubilized. Second, $29-34 \%$ of the solubilized and unfermented saccharides recovered in the broths of firstround fermentations were glucans. These saccharides were lost in downstream processing making them unavailable for conversion to end-products. Finally, washing biomass reduces/eliminates fermentation inhibitors as well as readily solubilized sugars $[7,21]$, but continued hydrolysis may lead to the generation of new inhibitors.
Specifically, the second-round fermentations showed decreased solubilization and conversion efficiencies at increased biomass loadings (Fig. 2b) similar to the firstround fermentations.

Given the fermentative capabilities observed in the $17.5 \mathrm{~g} / \mathrm{L}$ Avicel conditions (Fig. 1c), anabolic limitation due to medium composition or $\mathrm{pH}$-dependent inhibition is considered unlikely explanations for the accumulation of unfermented glucan equivalents in cultures broths. Experiments designed to investigate metabolic inhibition showed robust fermentation by $C$. thermocellum in terms of total soluble sugar utilization (Table 3). Significant changes included the reduction of ethanol and formate titers in the condition containing 50\% supernatant from the original $17.5 \mathrm{~g} / \mathrm{L}$ Avicel fermentation. While there was a 78 and $65 \%$ reduction in the net production of ethanol and formate, respectively, compared to the control condition, the titers of these metabolites were actually the highest observed when accounting for end-product carryover from the initial supernatant broths. As the minor changes in substrate utilization cannot account for these differences, these reductions likely represent endproduct induced metabolic shifts. End-product-based feedback inhibition has been previously noted in C. thermocellum fermentations [29]. In that study, increased ethanol titers were observed to lead to an increase in acetate production. The strain used here, however, is a phosphotransacetylase/lactate dehydrogenase mutant [25], which limits its potential to redirect its metabolites to acetate or lactate. Since significant increases in the metabolites assayed here were not observed (Table 3), it is presumed that metabolic shifts led to increases in amino acids and/or other "overflow" metabolites such as malate, isobutanol, meso-2,3-butanediol, etc. as has been previously reported for growth on model substrates $[5,12,26]$. Production of these metabolites can account for up to $30 \%$ of total carbon depending on Avicel loading [12] and likely comprise a large fraction of the undetected carbon in our Avicel mass balances (Table 1) and the end-product induced shifts observed (Table 3, Fig. 3). The effect of these metabolites on C. thermocellum's hydrolysis machinery has not yet been investigated. However, a recent study has shown that the production of "overflow" metabolites is relatively muted during $C$. thermocellum switchgrass fermentations making these compounds unlikely contributors to the switchgrassderived inhibition observed here [30].

Recently, it has been determined that the non-metabolizable pentose sugar, xylose, can act as a significant electron sink for C. thermocellum metabolism [31]. Integrated omics-analyses of $C$. thermocellum switchgrass fermentations have further suggested that significant carbon flux is directed away from glycolytic compounds 
towards alternative pathways in response to increased solubilized C5 intermediates that accumulate throughout fermentation [30]. While electron loss to non-metabolized lignocellulose-derived compounds may partly explain differences in achievable titers between model and real-world substrates, the extent that this is possible in $C$. thermocellum fermentations requires further investigation. In addition, while non-target electron loss is important to consider in attempts to industrialize ethanol production using $C$. thermocellum, these shifts do not explain why fermentable saccharides remain unfermented in culture broths after 10 days.

Hydrolysis was another process shown to be vulnerable to inhibition. Specifically, at the initial 25 and $50 \mathrm{~g} / \mathrm{L}$ switchgrass loadings, the solubilized, but unfermented glucose equivalents represent 12 and $11 \%$, respectively, of the initial glucan provided. In those same fermentations, however, the solubilization efficiency decreased by 17 and $26 \%$ relative to the $10 \mathrm{~g} / \mathrm{L}$ loading (Table 2 ). The data in Fig. 3 further show that the supernatants from the 25 and $50 \mathrm{~g} / \mathrm{L}$ loadings had the most detrimental effect on Avicel solubilization. All conditions showed significant $(p<0.05)$ inhibition of total Avicel solubilization relative to the control. As cultures containing Avicel-derived supernatants would have no lignocellulose-derived inhibitors, the most plausible explanation is that $C$. thermocellum fermentation products inhibited cellulase activity. Ethanol and other fermentation end-products have been reported to non-competitively inhibit fungal cellulases with concentrations as low as $24 \mathrm{mM}(1.09 \mathrm{~g} / \mathrm{L})$ ethanol leading to significant reductions in activity $[19,32,33]$. Initial ethanol concentrations here ranged from 6 to $59 \mathrm{mM}$ depending on the source of the spent supernatant, yet absolute titers exceeded $100 \mathrm{mM}(4.6 \mathrm{~g} / \mathrm{L})$ in all conditions by the end of the hydrolysis experiments. The high titers formed during the course of the experiment may have crossed a threshold concentration, where continued C. thermocellum cellulase activity became inhibited. Multiple ethanol tolerant strains have been reported, which in some cases have improved total solubilization capabilities, showing that this barrier can be overcome for C. thermocellum [34-37].

The switchgrass-derived supernatants were more inhibitory than those derived from Avicel fermentations (Fig. 3). In these cases, fermentation products alone cannot explain the reduction in solubilization. This is particularly evident in the first-round switchgrass fermentations, where end-product concentrations were significantly lower than those in the Avicel fermentations and did not approach the titers attained on the secondround Avicel fermentations. At the exclusion of $C$. thermocellum metabolites inhibiting hydrolysis, it suggests that the basis for inhibition is derived from the solubilization of switchgrass itself.
Recent studies have shown the adverse effect that lignin has on enzyme accessibility and carbohydrate solubilization in C. thermocellum fermentations with technological approaches such as in situ ball milling showing promise to reduce the recalcitrance barrier [38, 39]. Accessibility, however, does not explain the reduced solubilization of Avicel in the spent supernatant experiments observed here. The solubilization of lignin is considered to be quantitatively insignificant in C. thermocellum switchgrass fermentations [3], suggesting that the higher inhibition observed in the switchgrass-derived supernatants is not due to lignin-derived compounds.

Other switchgrass-derived components, such as hemicellulose or pectin hydrolysis products, may contribute to hydrolysis inhibition. Soluble xylo-oligomers are known to inhibit cellulase activity [40]. This may be important in high-solid loading fermentations as C. thermocellum is known to proportionately solubilize cellulose and hemicellulose fractions equally [3, 9]. In the $50 \mathrm{~g} / \mathrm{L}$ loadings tested here, xylose equivalents reached concentrations of $\sim 5 \mathrm{~g} / \mathrm{L}$ at the end of 10 days, which is higher than concentrations needed to reduce activity of fungal cellulases [40]. These concentrations, however, reflect measurements performed in homogenized supernatant samples, where diffusion is not limited. In high-solid loadings, mass transfer issues are known to affect oligosaccharide diffusion leading to high localized sugar concentrations $[16,18]$. The effects of high localized concentrations may have greater physiological effects on $C$. thermocellum hydrolysis and metabolism than can simply be predicted by determining product concentrations at the end of fermentation.

Fungal cellulases have also been reportedly inhibited by mixed xylo-glucan oligomers [41]. In that study, the inhibitory effect of the oligomers was significantly and differentially reduced after treatment with xylanases, xyloglucanases, or lichenases, suggesting that multiple oligomers contribute in concert to the reduction in cellulase activity observed. Bayer \& Lamed [42] have reported that pectin hydrolysis products also reduce the cellulose-hydrolyzing activity of purified C. thermocellum cellulosomes. Removal of the low-molecular weight pectin breakdown products restored the hydrolytic activity, however. While the hemicellulose and pectin deconstructing capabilities of $C$. thermocellum have been well documented $[3,9,43]$, monoculture environments lack a sink for fermentation of the breakdown products. The catabolism of these products would enable their removal from fermentation broths potentially alleviating the inhibition observed. Additional studies designed to determine the chemical nature and structure of $C$. thermocellum hydrolysis inhibitors are warranted. Such insights could be useful in fully elucidating the inhibitory 
mechanism(s) and allow the development of new strategies to overcome inhibition.

\section{Conclusions}

Overcoming hurdles related to the recalcitrance barrier, metabolic inhibition and addressing inhibition of hydrolysis are likely required for the industrialization of C. thermocellum or other bioconversion strategies for lignocellulosic biofuel production. Efforts to reduce the recalcitrance of minimally pretreated feedstocks are well underway through the use of genetically engineered or natural plant variants that have altered cell wall compositions. For continued improvements to microbial bioconversion, however, the data presented here suggest that inhibition of hydrolysis plays a greater role in reducing biofuel production at higher biomass loadings than does metabolic inhibition. Accordingly, successful efforts to reduce inhibition of hydrolysis may allow significant steps forward in applying CBP with C. thermocellum to convert industrially relevant biomass loadings to fuels and chemicals.

\section{Methods}

\section{Bacterial strains, medium and growth}

Lab stocks of C. thermocellum M1570 [25] were used throughout this study. Cultures were grown in Medium for Thermophilic Clostridia (MTC) as described [44] with the following exceptions: (i) MOPS buffer was increased from 5 to $10 \mathrm{~g} / \mathrm{L}$ and (ii) the initial $\mathrm{pH}$ of the medium was 7.2-7.4. Switchgrass was milled in a Wiley mill using a 20 mesh screen (Thomas Scientific, Swedesboro, NJ). For the first-round fermentations, Avicel or switchgrass was autoclaved in $25 \mathrm{~mL}$ of Milli-Q water (Millipore Corporation, Billerica, MA) under a $100 \%$ nitrogen headspace. Preexperiments determined that autoclaving the switchgrass in this manner released $0.55 \mathrm{mM}$ acetate, $0.24 \mathrm{mM}$ acetate, or below detectable amounts of acetate in the 50, 25, or $10 \mathrm{~g} / \mathrm{L}$ loadings, respectively. Eight molar sodium hydroxide was used to neutralize the acetic acid released in the switchgrass containing bottles, whereas sterile Milli-Q water was added to bottles as necessary to normalize liquid addition across conditions. Twenty-five milliliters of filtersterilized 2X MTC medium was then added aseptically to each bottle and reiterative cycles of gassing:degassing with $100 \%$ nitrogen were performed. Prior to inoculating $(10 \% \mathrm{v} / \mathrm{v})$ the Avicel or switchgrass containing bottles, $C$. thermocellum was grown on $3.5 \mathrm{~g} / \mathrm{L}$ Avicel for $48 \mathrm{~h}$. All experiments were run for 10 days at $55{ }^{\circ} \mathrm{C}$ with orbital shaking at $100 \mathrm{rpm}$ unless otherwise noted.

\section{Sample processing and fermentation analyses}

During first-round fermentations, $1 \mathrm{~mL}$ of liquid was removed every $24 \mathrm{~h}$ for $\mathrm{pH}$ and fermentation end-product analyses. After each sampling, headspace pressure was removed by venting the bottles for $15 \mathrm{~s}$ inside an anaerobic chamber filled with an inlet gas of $5 \% \mathrm{H}_{2}, 10 \% \mathrm{CO}_{2}$, and $85 \% \mathrm{~N}_{2}$. At the end of fermentation, cultures were centrifuged at $8000 \times g$ for $15 \mathrm{~min}$ and the supernatants and pellets analyzed. Fermentation end-products in the supernatant were measured using a Waters Breeze 2 high performance liquid chromatography (HPLC) system (Waters Corp., Milford, MA) equipped with an Aminex HPX-87H column (Bio-Rad Laboratories) and a refractive index detector as described previously $[31,45]$. The column temperature was set to $60{ }^{\circ} \mathrm{C}$ and the mobile phase was $5 \mathrm{mM} \mathrm{H}_{2} \mathrm{SO}_{4}$ flowing at a rate of $0.6 \mathrm{~mL} / \mathrm{min}$. Soluble carbohydrate content was determined via quantitative saccharification assay NREL/ TP-510-42618 and HPLC method NREL/TP-510-42623 essentially as described [46] using an Aminex HPX-87P column set to $85^{\circ} \mathrm{C}$. Dry weight measurements of residual substrate/biomass and cell growth were determined by incubating culture pellets at $60{ }^{\circ} \mathrm{C}$ until a decrease in weight was no longer observed. Residual solids were then stored at $-20^{\circ} \mathrm{C}$ for use in second-round fermentations.

\section{Second-round fermentations}

Residual switchgrass samples from equivalent first-round loading concentrations were pooled together. The solids were washed with ultrapure water at a ratio of $1 \mathrm{~L}$ for every $2 \mathrm{~g}$ of solids and then again dried at $60{ }^{\circ} \mathrm{C}$ until a decrease in weight was no longer observed. The dried, spent switchgrass was then autoclaved in water under an $\mathrm{N}_{2}$ headspace and an equal volume of 2X MTC medium was added (as described above). Second-round fermentations were then performed identically to first-round fermentations with the following exceptions: (i) $6 \mathrm{~mL}$ cultures were used instead of $50 \mathrm{~mL}$ cultures and (ii) samples for end-product analyses were taken only immediately after inoculation and after 10 days of fermentation.

Residual supernatants from the first-round fermentations were combined and neutralized to $\mathrm{pH}=7.2$ using $8 \mathrm{M} \mathrm{NaOH}$. Milli-Q water was once again used to normalize the liquid addition to the supernatants and maintain a consistent dilution across samples. The neutralized supernatants were sterilized via vacuum filtration through at $0.22 \mu \mathrm{m}$ filter. For the metabolic inhibition studies, $3 \mathrm{~mL}$ of sterilized spent supernatant was combined with $3 \mathrm{~mL}$ of filter-sterilized fresh 2X MTC medium containing cellobiose. For the hydrolysis inhibition studies, Avicel was first autoclaved in $1.5 \mathrm{~mL}$ of water under an $\mathrm{N}_{2}$ headspace. After cooling, $3 \mathrm{~mL}$ of spent supernatant plus $1.5 \mathrm{~mL}$ of $4 \mathrm{X}$ filter-sterilized MTC medium was added to each bottle. All bottles were once again gassed:degassed with $\mathrm{N}_{2}$. Inoculum for the cellobiose containing cultures was grown for $24 \mathrm{~h}$ in MTC 
medium containing cellobiose or for $48 \mathrm{~h}$ in medium with Avicel as described above. Fermentations were run for 5 days (cellobiose) or 10 days (Avicel) and end-product and mass-balance analyses were conducted at $t=0$ and at the end of fermentation. To avoid substrate losses for the $t=0$ measurements, replicate bottles were prepared and sacrificed. The $t=0$ analyses of the sacrificed cultures were assumed to be equivalent to those allowed to incubate for the duration of the experiment.

For the second-round Avicel experiments, total solubilization was calculated as a function of the residual dry weight measurements plus detectable glucose and cellobiose as measured by HPLC. Values were measured in reference to a control condition that contained water instead of spent supernatant from the initial fermentations and are expressed as a percent reduction in total solubilization observed. Second-round fermentations for both cellobiose and Avicel conditions were run using biological triplicates with whole experiments duplicated $(n=6)$.

\section{Abbreviations}

CBP: consolidated bioprocessing; MTC: medium for thermophilic clostridia.

\section{Authors' contributions}

TJV and JGE conceived and designed the study. TJV, GMG, and JGE conducted the experiments. TJV and JGE analyzed the data and wrote the manuscript. All authors read and approved the final manuscript.

\section{Author details \\ ${ }^{1}$ BioEnergy Science Center, Oak Ridge National Laboratory, Oak Ridge, TN 37831-6038, USA. ${ }^{2}$ Biosciences Division, Oak Ridge National Laboratory, Oak Ridge, TN 37831-6038, USA. ${ }^{3}$ Present Address: Department of Biological Sci- ences, University of Calgary, Calgary, AB T2N 1N4, Canada.}

\section{Acknowledgements}

We would like to thank Brian Davison and Miguel Rodriguez Jr. for providing the milled switchgrass used in this study. Support for Gabriela Garcia was provided in part by the National GEM Consortium. This work was supported by the BioEnergy Science Center, the U.S. DOE Bioenergy Research Center supported by the Office of Biological and Environmental Research in the DOE Office of Science. Oak Ridge National Laboratory is managed by UT-Battelle, LLC, for the U.S. DOE under contract DE-AC05-000R22725.

This manuscript has been authored by UT-Battelle, LLC under Contract No. DE-AC05-00OR22725 with the U.S. Department of Energy. The United States Government retains and the publisher, by accepting the article for publication, acknowledges that the United States Government retains a non-exclusive, paid-up, irrevocable, worldwide license to publish or reproduce the published form of this manuscript, or allow others to do so, for United States Government purposes. The Department of Energy will provide public access to these results of federally sponsored research in accordance with the DOE Public Access Plan (http://energy.gov/downloads/doe-public-access-plan).

\section{Competing interests}

The authors declare that they have no competing interests.

\section{Publisher's Note}

Springer Nature remains neutral with regard to jurisdictional claims in published maps and institutional affiliations.
Received: 13 June 2017 Accepted: 8 August 2017

Published online: 30 November 2017

\section{References}

1. Tian L, Papanek B, Olson DG, Rydzak T, Holwerda EK, Zheng T, Zhou J, Maloney M, Jiang N, Giannone RJ, et al. Simultaneous achievement of high ethanol yield and titer in Clostridium thermocellum. Biotechnol Biofuels. 2016:9:116.

2. Akinosho $\mathrm{H}$, Yee $\mathrm{K}$, Close D, Ragauskas A. The emergence of Clostridium thermocellum as a high utility candidate for consolidated bioprocessing applications. Front Chem. 2014;2:66.

3. Paye JM, Guseva A, Hammer SK, Gjersing E, Davis MF, Davison BH, Olstad J, Donohoe BS, Nguyen TY, Wyman CE, et al. Biological lignocellulose solubilization: comparative evaluation of biocatalysts and enhancement via cotreatment. Biotechnol Biofuels. 2016;9:8.

4. Kim SK, Groom J, Chung D, Elkins J, Westpheling J. Expression of a heat-stable NADPH-dependent alcohol dehydrogenase from Thermoanaerobacter pseudethanolicus 39E in Clostridium thermocellum 1313 results in increased hydroxymethylfurfural resistance. Biotechnol Biofuels. 2017; 10:66.

5. Papanek B, Biswas R, Rydzak T, Guss AM. Elimination of metabolic pathways to all traditional fermentation products increases ethanol yields in Clostridium thermocellum. Metab Eng. 2015;32:49-54.

6. Wilson CM, Rodriguez M Jr, Johnson CM, Martin SL, Chu TM, Wolfinger RD, Hauser LJ, Land ML, Klingeman DM, Syed MH, et al. Global transcriptome analysis of Clostridium thermocellum ATCC 27405 during growth on dilute acid pretreated Populus and switchgrass. Biotechnol Biofuels. 2013;6:179.

7. Yee KL, Rodriguez M Jr, Thompson OA, Fu C, Wang ZY, Davison BH, Mielenz JR. Consolidated bioprocessing of transgenic switchgrass by an engineered and evolved Clostridium thermocellum strain. Biotechnol Biofuels. 2014;7:75.

8. Agbor V, Zurzolo F, Blunt W, Dartiailh C, Cicek N, Sparling R, Levin DB. Single-step fermentation of agricultural hemp residues for hydrogen and ethanol production. Biomass Bioenergy. 2014;64:62-9.

9. Shao X, DiMarco K, Richard TL, Lynd LR. Winter rye as a bioenergy feedstock: impact of crop maturity on composition, biological solubilization and potential revenue. Biotechnol Biofuels. 2015;8:35.

10. Archambault-Leger $V$, Shao $X$, Lynd LR. Integrated analysis of hydrothermal flow through pretreatment. Biotechnol Biofuels. 2012;5:49.

11. Yee KL, Rodriguez M Jr, Tschaplinski TJ, Engle NL, Martin MZ, Fu C, Wang ZY, Hamilton-Brehm SD, Mielenz JR. Evaluation of the bioconversion of genetically modified switchgrass using simultaneous saccharification and fermentation and a consolidated bioprocessing approach. Biotechnol Biofuels. 2012;5(1):81.

12. Holwerda EK, Thorne PG, Olson DG, Amador-Noguez D, Engle NL, Tschaplinski TJ, van Dijken JP, Lynd LR. The exometabolome of Clostridium thermocellum reveals overflow metabolism at high cellulose loading. Biotechnol Biofuels. 2014;7:155.

13. Jin M, Sarks C, Bals BD, Posawatz N, Gunawan C, Dale BE, Balan V. Towards high solids loading process for lignocellulosic biofuel production at a low cost. Biotechnol Bioeng. 2017;114(5):980-9.

14. Islam R, Cicek N, Sparling R, Levin D. Effect of substrate loading on hydrogen production during anaerobic fermentation by Clostridium thermocellum 27405. Appl Microbiol Biotechnol. 2006;72(3):576-83.

15. Islam R, Cicek N, Sparling R, Levin D. Influence of initial cellulose concentration on the carbon flow distribution during batch fermentation by Clostridium thermocellum ATCC 27405. Appl Microbiol Biotechnol. 2009;82(1):141-8.

16. Zhang J, Shao X, Lynd LR. Simultaneous saccharification and cofermentation of paper sludge to ethanol by Saccharomyces cerevisiae RWB222. Part II: investigation of discrepancies between predicted and observed performance at high solids concentration. Biotechnol Bioeng. 2009;104(5):932-8.

17. Xue S, Uppugundla N, Bowman MJ, Cavalier D, Da Costa Sousa L, ED B, Balan V. Sugar loss and enzyme inhibition due to oligosaccharide 
accumulation during high solids-loading enzymatic hydrolysis. Biotechnol Biofuels. 2015;8:195.

18. Kristensen JB, Felby C, Jorgensen $\mathrm{H}$. Yield-determining factors in high-solids enzymatic hydrolysis of lignocellulose. Biotechnol Biofuels. 2009;2(1):11.

19. Podkaminer KK, Kenealy WR, Herring CD, Hogsett D, Lynd LR. Ethanol and anaerobic conditions reversibly inhibit commercial cellulase activity in thermophilic simultaneous saccharification and fermentation (tSSF). Biotechnol Biofuels. 2012;5:43

20. Jin M, Gunawan C, Balan V, Dale BE. Consolidated bioprocessing (CBP) of AFEX ${ }^{\mathrm{TM}}$-pretreated corn stover for ethanol production using Clostridium phytofermentans at high solids loading. Biotechnol Bioeng. 2012;109(8):1929-36.

21. Basen M, Rhaesa AM, Kataeva I, Prybol CJ, Scott IM, Poole FL, Adams MW. Degradation of high loads of crystalline cellulose and of unpretreated plant biomass by the thermophilic bacterium Caldicellulosiruptor bescii. Bioresour Technol. 2014;152:384-92.

22. Kataeva I, Foston MB, Yang S-J, Pattathil S, Biswal AK, Poole li FL, Basen M, Rhaesa AM, Thomas TP, Azadi P, et al. Carbohydrate and lignin are simultaneously solubilized from unpretreated switchgrass by microbial action at high temperature. Energy Environ Sci. 2013;6(7):2186.

23. David K, Ragauskas AJ. Switchgrass as an energy crop for biofuel production: a review of its ligno-cellulosic chemical properties. Energy Environ Sci. 2010;3(9):1182.

24. Lemus R, Brummer EC, Moore KJ, Molstad NE, Burras CL, Barker MF. Biomass yield and quality of 20 switchgrass populations in southern lowa, USA. Biomass Bioenergy. 2002;23(6):433-42.

25. Argyros DA, Tripathi SA, Barrett TF, Rogers SR, Feinberg LF, Olson DG, Foden JM, Miller BB, Lynd LR, Hogsett DA, et al. High ethanol titers from cellulose by using metabolically engineered thermophilic, anaerobic microbes. Appl Environ Microbiol. 2011;77(23):8288-94.

26. Ellis LD, Holwerda EK, Hogsett D, Rogers S, Shao X, Tschaplinski T, Thorne $P$, Lynd LR. Closing the carbon balance for fermentation by Clostridium thermocellum (ATCC 27405). Bioresour Technol. 2012;103(1):293-9.

27. Dumitrache A, Wolfaardt G, Allen G, Liss SN, Lynd LR. Form and function of Clostridium thermocellum biofilms. Appl Environ Microbiol. 2013:79(1):231-9.

28. Shao X, Jin M, Guseva A, Liu C, Balan V, Hogsett D, Dale BE, Lynd L. Conversion for Avicel and AFEX pretreated corn stover by Clostridium thermocellum and simultaneous saccharification and fermentation: insights into microbial conversion of pretreated cellulosic biomass. Bioresour Technol. 2011;102(17):8040-5.

29. RydzakT, Levin DB, Cicek N, Sparling R. End-product induced metabolic shifts in Clostridium thermocellum ATCC 27405. Appl Microbiol Biotechnol. 2011;92(1):199-209.

30. Poudel S, Giannone RJ, Rodriguez M Jr, Raman B, Martin MZ, Engle NL, Mielenz JR, Nookaew I, Brown SD, Tschaplinski TJ, et al. Integrated omics analyses reveal the details of metabolic adaptation of Clostridium thermocellum to lignocellulose-derived growth inhibitors released during the deconstruction of switchgrass. Biotechnol Biofuels. 2017;10:14.

31. Verbeke TJ, Giannone RJ, Klingeman DM, Engle NL, Rydzak T, Guss AM, Tschaplinski TJ, Brown SD, Hettich RL, Elkins JG. Pentose sugars inhibit metabolism and increase expression of an AgrD-type cyclic pentapeptide in Clostridium thermocellum. Sci Rep. 2017;7:43355.
32. Ghosh P, Pamment NB, Martin WRB. Simultaneous saccharification and fermentation of cellulose: effect of $\beta$-D-glucosidase activity and ethanol inhibition of cellulase. Enzyme Microb Technol. 1982;4:425.

33. Takagi M. Inhibition of cellulase by fermentation products. Biotechnol Bioeng. 1984;26:1506-7.

34. Brown SD, Guss AM, Karpinets TV, Parks JM, Smolin N, Yang S, Land ML, Klingeman DM, Bhandiwad A, Rodriguez M Jr, et al. Mutant alcohol dehydrogenase leads to improved ethanol tolerance in Clostridium thermocellum. Proc Natl Acad Sci USA. 2011;108(33):13752-7.

35. Herrero AA, Gomez RF. Development of ethanol tolerance in Clostridium thermocellum: effect of growth temperature. Appl Environ Microbiol. 1980;40(3):571-7.

36. Shao X, Raman B, Zhu M, Mielenz JR, Brown SD, Guss AM, Lynd LR. Mutant selection and phenotypic and genetic characterization of ethanoltolerant strains of Clostridium thermocellum. Appl Microbiol Biotechnol. 2011;92(3):641-52.

37. Tailliez $\mathrm{P}$, Girard $\mathrm{H}$, Longin $\mathrm{R}$, Beguin $\mathrm{P}$, Millet J. Cellulose fermentation by an asporogenous mutant and an ethanol-tolerant mutant of Clostridium thermocellum. Appl Environ Microbiol. 1989;55(1):203-6.

38. Dumitrache A, Tolbert A, Natzke J, Brown SD, Davison BH, Ragauskas AJ. Cellulose and lignin colocalization at the plant cell wall surface limits microbial hydrolysis of Populus biomass. Green Chem. 2017;19(9):2275-85

39. Balch ML, Holwerda EK, Davis MF, Sykes RW, Happs RM, Kumar R, Wyman $C E$, Lynd LR. Lignocellulose fermentation and residual solids characterization for senescent switchgrass fermentation by Clostridium thermocellum in the presence and absence of continuous in situ ball-milling. Energy Environ Sci. 2017;10(5):1252-61.

40. Qing Q, Yang B, Wyman CE. Xylooligomers are strong inhibitors of cellulose hydrolysis by enzymes. Bioresour Technol. 2010;101(24):9624-30.

41. Kont R, Kurasin M, Teugjas H, Valjamae P. Strong cellulase inhibitors from the hydrothermal pretreatment of wheat straw. Biotechnol Biofuels. 2013;6(1):135.

42. Bayer EA, Lamed R. The cellulose paradox: pollutant par excellence and/or a reclaimable natural resource? Biodegradation. 1992;3:171-88.

43. Chakraborty S, Fernandes VO, Dias FM, Prates JA, Ferreira LM, Fontes CM, Goyal A, Centeno MS. Role of pectinolytic enzymes identified in Clostridium thermocellum cellulosome. PLoS ONE. 2015;10(2):e0116787.

44. Holwerda EK, Hirst KD, Lynd LR. A defined growth medium with very low background carbon for culturing Clostridium thermocellum. J Ind Microbiol Biotechnol. 2012;39(6):943-7.

45. Chung D, Verbeke TJ, Cross KL, Westpheling J, Elkins JG. Expression of a heat-stable NADPH-dependent alcohol dehydrogenase in Caldicellulosiruptor bescii results in furan aldehyde detoxification. Biotechnol Biofuels. 2015;8:102

46. Dumitrache A, Akinosho H, Rodriguez M Jr, Meng X, Yoo CG, Natzke J, Engle NL, Sykes RW, Tschaplinski TJ, Muchero W, et al. Consolidated bioprocessing of Populus using Clostridium (Ruminiclostridium) thermocellum: a case study on the impact of lignin composition and structure. Biotechnol Biofuels. 2016;9:31.

\section{Submit your next manuscript to BioMed Central and we will help you at every step:}

- We accept pre-submission inquiries

- Our selector tool helps you to find the most relevant journal

- We provide round the clock customer support

- Convenient online submission

- Thorough peer review

- Inclusion in PubMed and all major indexing services

- Maximum visibility for your research

Submit your manuscript at www.biomedcentral.com/submit
BioMed Central 